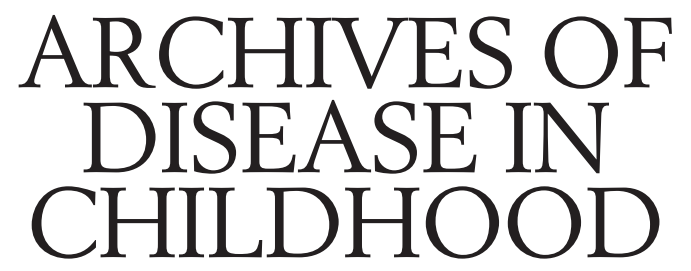

The Fournal of the Royal College of Paediatrics and Child Health

\title{
Annotations
}

\section{Withdrawing and withholding treatment: comments on new guidelines}

A new practice framework for clinicians has recently been issued by the Royal College of Paediatrics and Child Health through their Ethics Advisory Committee. ${ }^{1}$ It deals with babies and children for whom intensive treatment may not be in their best interest. These are difficult cases. Absolute certainty is rarely possible; there are inevitably issues of conscience and conflict, which add to the burden individuals carry. Do the RCPCH guidelines address the concerns of doctors and nurses at the cotside? Will they be of practical help?

The guidelines are based on evidence from experts, and discussion by carefully selected focus groups, both useful ways to further thinking on a subject. But these methods lack the rigour of empirical data collected by scientific research. Does research evidence confirm expert opinion? If it does, the guidelines will carry greater weight.

We looked at the RCPCH document in relation to the expressed concerns and stresses of staff who work in neonatal intensive care units. In a recent survey ${ }^{2}$ we carried out in depth interviews with 57 doctors and 119 nurses currently employed in six neonatal intensive care units in Scotland. The units were selected to reflect different geographical, cultural, and social factors; the sample was stratified to represent all grades and levels of experience.

In principle, the RCPCH guidelines do address most of the issues that concern clinicians, but we highlight five areas that warrant further discussion.

\section{Team involvement}

Time and again the RCPCH document refers to the need to listen carefully to all those participating in the care of the child. The committee calls for "open and timely communication", "reasoning together", a "corporate moral responsibility". Specifically they advise that "all members of the clinical team should have an opportunity to voice their feelings". This is timely reinforcement. In five of the six units we surveyed there was one group - the nurses - who felt they were insufficiently involved in discussions. In two of the units only one of the consultants ever consulted the nurses - by the consultants' admission as well as in the nurses' perceptions. This caused considerable tension within the team. In all the six units, when our respondents considered specific cases where treatment withdrawal was being considered, over half $(55 \%)$ of the nurses (in contrast to only $21 \%$ of the doctors) cited doctor-nurse conflict as a cause of tension. The nurses repeatedly commented that their views were underrepresented. While there was rarely disagreement about the final decision, more than a third $(38 \%)$ of the nurses and $30 \%$ of the doctors singled out the timing of events as a major area of tension within the team. In addition, $22 \%$ of the nurses, but only $9 \%$ of the doctors, identified the way the case was managed as the factor causing unease. Team effort has to be real, not just a paper exercise, and this new document comes as welcome reiteration of the message.

\section{The role of junior doctors}

In the RCPCH document, emphasis is rightly placed on the necessity not to hurry any decision. Facts have to be accumulated and options explored. Junior doctors, the RCPCH states, should administer life sustaining treatment until senior more experienced doctors take over. This is wise counsel and the policy in most units; however, the implications should not be underestimated. In our interviews, junior doctors eloquently described a number of emergency situations they had experienced and the stress of carrying out such instructions in the face of overwhelming evidence that starting intensive treatment was ill advised. Their consciences were greatly troubled; defence of their actions to parents sounded lame; and senior nurses sometimes compounded their stress by making it very plain that the doctor had made a mistake. Perhaps this is an area for particular attention.

Withdrawal of procedures designed to alleviate pain or promote comfort

"Where treatment aimed at alleviation or cure of a condition has been withdrawn, the clinical team has a duty always to offer palliative care," states the RCPCH. One of the findings of our inquiry was that practices and procedures vary considerably both between and within units. One area of major difference relates to the use of drugs. Opinions differ regarding the giving of opiates and paralysing agents. Some teams carry out a series of tests to confirm a bleak prognosis but first they withdraw all medication to be sure that no symptoms are masked. Others orchestrate deaths to be sensitive to parents' needs, using drugs in various doses and combinations. Strong opinions were voiced to us by staff who construed these things very differently. The distinction between the means and the intention made in these guidelines appears helpful 
and should reassure both clinicians and parents. Giving a medicine for the purpose of relieving pain or distress and not to cause or hasten death is legal and can be appropriate management. It is not necessary to withdraw paralysing agents before withdrawing respiratory support in a baby being managed with paralytics, but it would be considered euthanasia to induce muscle paralysis deliberately to avoid the terminal gasping that sometimes follows withdrawal of ventilation.

\section{Second opinion}

The guidelines suggest that obtaining a second opinion for legal reasons as well as clinical assurance might be adopted in the same way as for termination of pregnancy and brain stem death. Although for all other grades we took a stratified sample, all consultants in the study units were given the opportunity to be interviewed; 21 of the 22 agreed. Half of the doctors who accepted responsibility for the decision making admitted, in the privacy of a confidential interview, that they found it burdensome, and almost all recognised that it could be emotionally draining. Over the years they tended to develop ways of dealing with the stress that cushioned them from the full effects of each case. One avenue that most acknowledged as supportive was discussion with colleagues. Reassurance and peace of mind came from other competent consultants with expert knowledge of neonatology similarly concluding that treatment should be withdrawn. Some consultants working in district general hospital units indicated that they consulted experienced colleagues from regional university based centres with established reputations to gain backing for their decisions. To some extent the doctors have already built in a legal defence as well as a personal support system. $^{3}$

\section{Withholding feeds}

One area barely mentioned in the guidelines is the withholding of feeds. The role of assisted feeding, the $\mathrm{RCPCH}$ says, "should be considered very carefully and discussed fully with the family." Although withholding artificial feeds in situations where oral feeding is not possible or cannot be tolerated (for example, severely birth asphyxiated babies who are profoundly damaged) is practised in only a minority of units, it is a source of acute stress, particularly for nurses. The consultants explain logically and persuasively that this course of action demonstrates conclusively to the family that the outlook is bleak, but to nurses it feels like withholding basic comfort and dignity. This is an area of practice that must be given detailed consideration in the future. From our discussions with all those involved it appears that implementing the instruction can feel very different from giving it. Many clinicians we interviewed were unaware that such a practice is still adopted, and this could account for its scant attention in the $\mathrm{RCPCH}$ framework.

\section{Conclusion}

The RCPCH framework does address the concerns of clinicians. Empirical evidence supports its conclusions in general. The guidelines will provide reassurance as well as a source of reference. But consideration of the recommendations should prompt neonatal teams everywhere to examine their actual practices honestly to see whether an infrastructure is available to support all levels of staff engaged in these crucial decisions.

We are enormously indebted to the doctors and nurses who gave such valuable insights into their experiences and thinking. The study mentioned was funded in its entirety by the Scottish Office Home and Health Department. Professor AGM Campbell gave helpful comments on a first draft of this paper.

HAZEL E MCHAFFIE

Medical Ethics, Department of Medicine,

University of Edinburgh,

Royal Infirmary,

Lauriston Place,

Edinburgh EH3 9YW, UK

email: Hazel.McHaffie@ed.ac.uk

Perth Royal Infirmary,

PETER W FOWLIE

Taymount Terrace,

Perth PH1 1 NX, UK

1 Royal College of Paediatrics and Child Health. Withholding or withdrawing life saving treatment in children. A framework for practice. London: $\mathrm{RCPCH}$, 1997.

2 McHaffie HE, Fowlie PW. Life, death and decisions: doctors and nurses reflect on neonatal practice. Cheshire: Hochland and Hochland, 1996.

3 Bolam v Friern Hospital Management Committee. QBD (1957) 2 ALL ER 118.

\section{Toddler diarrhoea: more a nutritional disorder than a disease}

For the practising paediatrician toddler diarrhoea or chronic non-specific diarrhoea is a frequently encountered disorder. Every paediatrician knows the tableau vivant of extremely worried parents around a sparkling, healthy looking child who appears to be unaware of all the commotion. After a thorough clinical history and a simple physical examination, the diagnosis is often obvious. Both defecation frequency and stool consistency are very different from other children. The stools are foul smelling, watery, and contain mucus with undigested vegetable material. The parents are likely to report a short mouth to anus transit time. Usually, the children have no failure to thrive and they present in a good nutritional state. Abdominal pain may be present in a minority. In the developed, Western countries, toddler diarrhoea is by far the most frequent cause of chronic diarrhoea in children between 1 and 5 years of age. Since the first description in 1966 , research on this common condition has mainly concerned its nutritional aspects. ${ }^{1-4}$

\section{What is a normal stool?}

The defecation pattern of healthy young children is extremely variable in consistency and frequency. Important variations in bowel habits exist between different populations. Normal values for daily frequency and total bowel transit time have been reported for children in industrialised countries. ${ }^{5}$ For a toddler it may not be abnormal to have more than three soft and occasionally loose stools each day with visible food remnants. In this respect, colonic water absorption and colonic transit are extremely important for faecal consistency. Of all water entering the proximal colon, more than $80 \%$ will be retrieved. On a body weight base, young children need to handle more fluid, and they have less effective colonic water absorption and higher faecal water losses as a consequence. ${ }^{6}$ In general, it is not well recognised that the water content of normally formed stools is as high as $70-75 \% .^{7}$ In a runny, watery stool this will be $90 \%{ }^{7}$ Therefore, a relatively small increase in water can make all the difference in the parental perception of 
health and disease. In this respect the important role of the colon is further illustrated in studies on stool form in healthy individuals. Stool form is mainly determined by colonic transit and not by small intestinal passage. ${ }^{8}$

\section{Proposed mechanisms}

While most investigators agree that intestinal motility is disturbed in children with toddler diarrhoea at the time of diagnosis, there is no indisputable evidence that it is the primary mechanism of the condition. Research has mainly focused on the small intestine. Normally, duodenal migrating motor complexes result in propulsive activity in the fasting condition and they disappear in response to a meal. In one study these complexes were not interrupted following intraduodenal glucose instalment. ${ }^{9}$ This may result in a shorter small intestinal transit time, but compared with healthy controls no differences have been observed in total mouth to caecum transit time measured by breath hydrogen tests. ${ }^{10}$ As most clinicians agree there is a significantly shortened mouth to anus transit time, this puts focus on the motility of the large intestine and a reduced colonic transit time.

It is not clear whether we can include toddler diarrhoea in the larger concept of the irritable bowel syndrome of infancy. ${ }^{11}$ This concept overlaps with childhood constipation and recurrent abdominal pain. ${ }^{11}{ }^{12}$ While these two symptoms are frequently seen together, this seems not to be the case in toddler diarrhoea. One rarely notices a history of constipation in these children, and abdominal pain at presentation is seen in only a small minority. Long time follow up studies are clearly needed for all three conditions.

Nutritional factors are increasingly recognised as playing a key role in both the pathogenesis and treatment of toddler diarrhoea; they may also explain the growing incidence of the condition. In retrospective studies, toddler diarrhoea has been found in children consuming very low fat diets to prevent coronary artery disease, ${ }^{2}$ on very high fluid intake, ${ }^{3}$ and with high fluid osmolality. ${ }^{13}$ In these studies the obvious interventions appeared to be beneficial, but no attention was given to displacement of other components in the diet, and no prospective intervention studies have been reported.

In the past two decades, a number of studies have been performed using breath hydrogen tests to investigate carbohydrate malabsorption. In many Western countries apple juice is extremely popular in young children. Parents perceive apple juice as natural, healthy, nutritious, and relatively inexpensive. In paediatric practice the raw apple diet has a very long reputation in diarrhoeal disorders, probably because of the water holding properties of the apple fibres. ${ }^{14}$ Hyams and Leichtner were the first to report apple juice as a cause of toddler diarrhoea and complete recovery after its withdrawal. ${ }^{13}$ These authors also reported positive breath hydrogen tests after consumption of apple juice, ${ }^{13}$ which made carbohydrate malabsorption the major domain for research in toddler diarrhoea.

\section{Carbohydrate malabsorption}

All fruit juices contain important, but varying amounts of fructose and glucose. Depending on the fruit, sucrose and sorbitol may also be present. Small intestinal absorption of glucose and sucrose is generally complete, but absorption of fructose ${ }^{15} 16$ and sorbitol ${ }^{17}$ is limited and may occasionally provoke gastrointestinal symptoms with abdominal distension, flatulence, abdominal pains, and diarrhoea. At first only sorbitol was incriminated although its concentrations are very low in apple juice. ${ }^{18}{ }^{19}$ Later studies suggested that high fructose intake ${ }^{20}$ or a competition between fructose and sorbitol to use the same intestinal transporter proteins are the main factors involved. ${ }^{21}$ It is remarkable that eminent nutritional committees have issued recommendations based principally on mere breath hydrogen tests without documentation of accompanying symptoms or signs of carbohydrate intolerance in the stools. The reports focused on fruit juices that have no excess of free fructose and contain no sorbitol-for example, grape and bilberry juice. ${ }^{22}{ }^{23}$ Manufacturers were keen to include these recommendations for advertising campaigns in a growing market. In the United States more than $\$ 200$ million is spent each year on bottled baby juice.

In a series of experiments we demonstrated that most healthy young children have positive breath hydrogen tests after fructose ingestion without signs of intolerance. Obviously, these healthy children can break down this malabsorbed carbohydrate efficiently by colonic bacterial fermentation. ${ }^{16}$ Similarly, even most children with an established diagnosis of toddler diarrhoea had small intestinal fructose malabsorption without diarrhoea. ${ }^{10}$ Ingestion of different juices including apple, grape or bilberry gave positive breath hydrogen tests, even after removal of fructose and glucose by yeast treatment. ${ }^{24}$ These results suggest that other components such as polysaccharides and oligosaccharides originating from the fruit or peel are fermented and contribute to the exhaled hydrogen.

In a randomised trial of children with a recent diagnosis of toddler diarrhoea who were free from symptoms after dietary advice, only reintroduction of normal clear apple juice resulted in the recurrence of diarrhoea; these children could tolerate cloudy apple juice. ${ }^{25}$ Cloudy juice is bottled immediately after pressing, whereas clear apple juice is industrially prepared by means of enzymatic treatment of the apple pulp to obtain a higher yield and an attractive clear product. The products therefore differ in the amount of dietary fibre and the amounts of indigestible monosaccharides and oligosaccharides. However, as the amounts of fructose and sorbitol were identical in both products, these studies further disclaim malabsorption of those carbohydrates as principal factors in toddler diarrhoea.

It is only recently that we have a better understanding of the interactions between fermentation and normal colonic function. The general view on the role of the colon for carbohydrates that are not absorbed in the small intestine is changing. Previously seen as an organ that might "salvage" these nutrients and prevent osmotic diarrhoea, the colon is now considered more as a complex metabolic factory where a constant flow of mainly complex carbohydrates is a prerequisite for proper function. In the proximal colon these carbohydrates are fermented by colonic bacterial flora into short chain fatty acids (SCFAs) - the main nutrients for colonocytes and important anions for colonic sodium and water absorption. SCFAs are believed to have feedback regulations on gastric emptying and small intestinal transit. ${ }^{26}$ In addition, SCFAs have a number of properties that may be important in maintaining normal bowel structure and function and preventing colon based diarrhoea. ${ }^{27}$ Whether these mechanisms are disturbed in the child with toddler diarrhoea remains unclear, but it provides an attractive new field of investigation.

\section{"Newtrition" versus nutrition}

In developed countries, the diet of children, especially of infants and toddlers, has changed dramatically over the past years. Paediatricians and other physicians are increasingly consulted not only for toddler diarrhoea but also for other health problems related to these changes. Ready-made products increasingly replace food prepared fully by parents. Here, new nutritional habits originate that go together with an increase in affluence. Drinking plain water is out of vogue. ${ }^{28}$ It has largely been replaced by fruit juice 


\section{Key messages}

- In developed countries toddler diarrhoea is the most frequent cause of chronic diarrhoea in 1-5 year old children

- Toddler diarrhoea has a typical dietary and clinical history

- Breath hydrogen tests have no place in the diagnostic process

- Treatment includes normalisation of feeding patterns according to the "four Fs": Fat, Fibre, Fluid, and Fruit juices

and squash. ${ }^{28}$ Drinks are consumed on a more or less constant basis, often by a drinking bottle. They provide a high number of calories and may diminish the appetite. Reports from the United States indicate that these mainly carbohydrate containing fluids contribute to unbalanced nutrition. ${ }^{29}$ In clinical practice we encounter young children having excess juice consumption as a contributing factor in non-organic failure to thrive. ${ }^{29}{ }^{30}$ In a cross sectional sample of healthy young children, excess fruit juice consumption was associated with short stature and obesity. ${ }^{31}$

Frequently, drinking fruit juice results in a high fluid intake with displacement of fat and fibre from the diet. More parents seem to be concerned with obesity and intend to offer low calorie drinks, not being aware of the fact that, because of its high carbohydrate content, fruit juice equals the caloric content of many popular dairy products. In the modern diet the intake of grain products, fruit, and vegetables is declining. Large numbers of children are not meeting minimum fibre intake recommendations. ${ }^{32}$ Consumption of most ready-made meals and a high juice intake further contributes to deficient fibre ingestion.

\section{Treatment}

After a thorough clinical history and a simple physical examination, the diagnosis is often obvious. The main message to the parents is reassurance on underlying serious gastrointestinal disorders and normalisation of the diet. Kneepkens and Hoekstra proposed a normalisation of the child's feeding pattern according to the "four Fs": Fat, Fibre, Fluid, and Fruit juices. ${ }^{4}$ As it seems that these children represent the end of a spectrum of normality, the dietary treatment will often be close to the borders of normal nutritional recommendations. Fat intake should be increased to at least $35 \%$, even $40 \%$, of total energy intake. Restoration of a pattern with well defined meals and snacks provides the opportunity for significant increases of fibre intake. Fruit juices, in particular clear apple juice, and other squashes should be limited to restore appetite at meal times. Drinks between meals are acceptable, but overconsumption should be discouraged. In almost all patients the efficacy of these dietary measures is such that it may even serve as a confirmation of the diagnosis. ${ }^{11}{ }^{25}$ Some authors have used aspirin, ${ }^{33}$ loperamide ${ }^{33}$ or mebeverine ${ }^{11}$ for cases refractory to dietary measures. Their effects last as long as they are given. As a consequence, medication seems to be unwarranted for a condition that does not hamper the child to thrive.

\section{Perspectives}

The problems in children with toddler diarrhoea often start following acute gastroenteritis. Instructed to prevent dehydration parents persistently offer clear liquid and therefore start a vicious cycle of dietary restrictions and continuing diarrhoea. A greater awareness of modern treatment of acute gastroenteritis with oral rehydration solutions to combat dehydration followed by rapid resumption of normal feeding 3-4 hours after rehydration will prevent toddler diarrhoea starting in many potential cases. ${ }^{34}$

Toddler health will benefit from widely accepted nutritional recommendations. A consensus on dietary fat and fibre will pave the road to practical recommendations. Not in the least these will have to include lifestyle related aspects.

\section{Conclusions}

It is evident that toddler diarrhoea is worrisome for many parents. It is a condition related to modern affluent societies where new nutritional practices have emerged. Related to these changes clinicians see children with toddler diarrhoea, nutritional deficiencies, and even manifest failure to thrive with stunting. The long term health effects remain uncertain. For paediatric medicine, fine tuned to the optimal nutrition for the young infant, the challenging field for nutritional research with toddlers remains largely unexplored.

Finally, what will be the thoughts of worried parents of a child with longstanding diarrhoea? Following an explanation and dietary advice, they may leave with some scepticism. The advice with regards to a normal healthy diet seems to be too simple and does not fit adequately into the expectations concerning modern specialist care. However, within days they will notice that this simple advice, if followed, is very effective.

J HANS HOEKSTRA

Department of Paediatrics,

Bosch Medicentrum,

5200 ME's-Hertogenbosch, Netherlands

1 Davidson $M$, Wasserman R. The irritable colon of childhood (chronic nonspecific diarrhea syndrome). F Pediatr 1966;69:1027-38.

2 Cohen SA, Hendricks KM, Eastham EJ, Mathis RK, Walker WA. Chronic nonspecific diarrhea. A complication of dietary fat restriction. Am $\mathcal{F}$ Dis Child 1979;133:490-2.

3 Greene HL, Ghishan FK. Excessive fluid intake as a cause of chronic diarrhea in young children. $\mathcal{F}$ Pediatr 1983;102:836-40.

4 Kneepkens CMF, Hoekstra JH. Chronic nonspecific diarrhea of childhood: pathophysiology and management. Pediatr Clin N Am 1996;43:375-90.

5 Weaver LT. Bowel habit from birth to old age $\mathcal{F}$ Pediatr Gastroenterol Nutr 1988;7:637-40.

6 Rhoads JM, Powell DW. Diarrhea. In: Walker WA, Durie PR, Hamilton JR, Walker-Smith JA, Watkins JB, eds. Pediatric gastrointestinal disease. Palker-Smith JA, Watkins JB, eds.

7 Wentzl HO, Fine KD, Schiller LR, Fordtran JS. Determinants of decreased fecal consistency in patients with diarrhea. Gastroenterology 1995;108: 1729-38.

8 Degen LP, Phillips SF. How well does stool form reflect colonic transit? Gut 1996;39:109-13.

9 Fenton TR, Harries JT, Milla PJ. Disordered small intestinal motility: a rational basis for toddlers' diarrhoea. Gut 1983;24:897-903.

10 Hoekstra $\mathrm{JH}$. Fructose breath hydrogen tests in infants with chronic non-specific diarrhoea. Eur F Pediatr 1995;154:362-4.

11 Fenton TR. The irritable bowel syndrome. A paediatric entity? In: Milla PJ, ed. Disorders of gastrointestinal motility in childhood. Chichester: John Wiley and Sons, 1988:101-7.

12 Keuzenkamp-Jansen CW, Fijnvandraat CJ, Kneepkens CMF, Douwes AC. Chronic functional constipation in childhood: diagnostic dilemmas and long-term results of medical treatment. Arch Dis Child 1996;75:36-51.

13 Hyams JS, Leichtner AM. Apple juice. An unappreciated cause of chronic diarrhea. Am $\mathcal{F}$ Dis Child $1985 \cdot 139: 503-5$.

14 Birnberg TL. Raw apple diet in the treatment of diarrheal conditions in children. Am $\mathcal{7}$ Dis Child 1933;45:18-24.

15 Kneepkens CMF, Vonk RJ, Fernandes J. Incomplete intestinal absorption of fructose. Arch Dis Child 1984;59:735-9.

16 Hoekstra JH, Van Kempen AAWM, Bijl SB, Kneepkens CMF. Fructose breath hydrogen tests. Arch Dis Child 1993;68:136-8.

17 Hyams JS. Chronic abdominal pain caused by sorbitol malabsorption. $\mathcal{f}$ Pediatr 1982;100:772-3.

18 Hyams JS, Etienne NL, Leichtner AM. Carbohydrate malabsorption following fruit juice ingestion in young children. Pediatrics 1988;82:64-8.

19 Hoekstra JH, Van Kempen AAMW, Kneepkens CMF. Apple juice malabsorption: fructose or sorbitol? F Pediatr Gastroenterol Nutr 1993;16: 39-43.

20 Kneepkens CMF, Douwes AC, Jakobs C. Apple juice, fructose, and chronic non-specific diarrhoea. Eur f Pediatr 1989;148:571-3.

21 Rumessen JJ, Gudmand-Høyer E. Functional bowel disease: malabsorption and abdominal distress after ingestion of fructose, sorbitol, and fructose-sorbitol mixtures Gastroenterology 1988;95:694-700.

22 American Academy of Pediatrics Committee on Nutrition. The role of fruit juice in the diets of young children. AAP News 1991;7(2):11.

23 Lifshitz F, Ament ME, Kleinman RE, et al. Role of juice carbohydrate malabsorption in chronic nonspecific diarrhea in children. $f$ Pediatr 1992;20:825-9. 
24 Hoekstra JH, Van den Aker JHL, Hartemink R, Kneepkens CMF. Fruit juice malabsorption: not only fructose. Acta Paediatr 1995:84:1241-4.

25 Hoekstra JH, Van den Aker JHL, Ghoos YF, Hartemink R, Kneepkens CMF. Fluid intake and industrial processing in apple juice induced chronic non-specific diarrhoea. Arch Dis Child 1995;73:126-30.

26 Ropert A, Cherbut C, Rozé, et al. Colonic fermentation and proximal gastric tone in humans. Gastroenterology 1996;111:289-96.

27 Roediger WEW. Famine, fibre, fatty acids, and failed colonic absorption: does fibre fermentation ameliorate diarrhea? F Parenter Enteral Nutr 1994; 18:4-8.

28 Petter LPM, Hourihane JO'B, Rolles CJ. Is water out of vogue? A survey of the drinking habits of 2-7 year olds. Arch Dis Child 1995;72:137-40.

29 Smith MM, Lifshitz F. Excess fruit consumption as a contributing factor in nonorganic failure to thrive. Pediatrics 1994;93:438-43.
30 Hourihane JO'B, Rolles CJ. Morbidity from excessive intake of high energy fluids: the "squash drinking syndrome". Arch Dis Child 1995;72:141-3.

31 Dennison BA, Rockwell HL, Baker S. Excess fruit juice consumption by preschool-aged children is associated with short stature and obesity. Pediatrics 1997;99:15-22.

32 Saldanha LG. Fibre in the diet of US children: results of national surveys. Pediatrics 1995;96:994-7.

33 Hamdi I, Dodge JA. Toddler diarrhoea: observations on the effect of aspirin and loperamide. F Pediatr Gastroenterol Nutr 1985;4:362-5.

34 Walker-Smith JA, Sandhu BK, Isolauri E, et al. Recommendations for feeding in childhood gastroenteritis. Guidelines prepared by the ESPGAN working group on acute diarrhoea. F Pediatr Gastroenterol Nutr 1997:24: $619-20$ 